\title{
Biomarkers for epileptogenesis in patients with autoimmune epilepsy
}

\author{
Batool F. Kirmani ${ }^{1,2}$, Katherine Au ${ }^{1}$, Seema Mir², Matthew Hogan², Dennis Kim², Pushpa Sharma ${ }^{3}$ \\ 'Department of Neurosciences, INOVA Fairfax Medical Campus, Falls Church, VA 22042, USA. \\ ${ }^{2}$ VCU School of Medicine, INOVA Fairfax Medical Campus, Falls Church, VA 22042, USA. \\ ${ }^{3}$ Department of Anesthesiology, Uniformed Services University of Health Sciences, Bethesda, MD 20814, USA.
}

Correspondence to: Prof. Batool F. Kirmani, Department of Neurosciences, Virginia Commonwealth University School of Medicine, INOVA Fairfax Medical Campus, Falls Church, VA 22042, USA. E-mail: bkirmani2@gmail.com

How to cite this article: Kirmani BF, Au K, Mir S, Hogan M, Kim D, Sharma P. Biomarkers for epileptogenesis in patients with autoimmune epilepsy. Neuroimmuno/ Neuroinflammation 2021;8:81-100.

http://dx.doi.org/10.20517/2347-8659.2020.29

Received: 9 Apr 2020 First Decision: 2 Jun 2020 Revised: 16 Jun 2020 Accepted: 28 Jun 2020 Available online: 21 Jun 2021

Science Editor: Mercè Falip Copy Editor: Cai-Hong Wang Production Editor: Tian Zhang

\begin{abstract}
Autoimmune epilepsy (AE) is a general term to describe recurrent seizures that have an immune-mediated origin. It is increasingly being recognized as a cause of epilepsy due to accumulating evidence supporting an immunemediated pathogenesis in patients who have shown resistance to traditional antiepileptic drugs (AEDs). The diagnosis of $A E$ is one of the exclusions. Currently, there are no strict diagnostic guidelines for $A E$, and it is similarly under-recognized. The importance of early diagnosis of $A E$ cannot be overstated, as prompt immunotherapy is important for seizure reduction. Further investigations into potential biomarkers are needed for early detection of $A E$ and include targeted immunotherapies in combination with AEDs. The goal of this review was to provide an overview of the following biomarkers that have been associated with AE: AMPAR, LGI1, CASPR2, DPPX, GABAAR, GABABR, GFAP, GlyR, mGluR5, NMDAR, VGCC (P/Q types), amphiphysin, ANNA-1, CRMP-5, GAD65, and Ma1/ Ma2 antibodies.
\end{abstract}

Keywords: Autoimmune epilepsy, biomarkers, drug-resistant seizures, immunotherapy, epileptogenesis

\section{INTRODUCTION}

Autoimmune epilepsy (AE) is a general term that describes inflammation of the central nervous system (CNS) and has been linked to several autoantibodies, the most common of which will be explored in this review $^{[1]}$. It is typically characterized by seizures classically found in limbic encephalitis (LE) or multifocal paraneoplastic disorders, and focal seizures appear to be predominant in clinical presentations ${ }^{[1]}$. However,

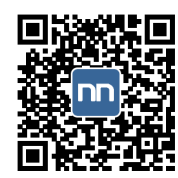


patients with AE may also present with a simple seizure and atypical symptoms such as lethargy, personality changes, psychiatric changes, or autonomic dysfunctions ${ }^{[2,3]}$. While autoimmune seizures are frequently observed early in the progression of the disease, the initial presentation and electroencephalogram (EEG) may be unremarkable ${ }^{[1]}$. It has been found that immunosuppressive treatment is the primary treatment regardless of the diverse neurologic symptoms associated with $\mathrm{AE}^{[1]}$. Due to these varying presentations of $\mathrm{AE}$, establishing a standard of care is challenging and is based on identifying potential patients by their clinical characteristics, their neural autoantibody tests, and their response to immunotherapy ${ }^{[1,2,4]}$. That said, a good basis for suspecting an autoimmune etiology is when there is variability in the clinical features of seizures, or when the epileptiform discharges arise from more than one focal origin ${ }^{[2]}$.

AE autoantibodies were first identified in the serum of patients with refractory epilepsy, indicating an epilepsy manifesting from an immune-related disorder ${ }^{[2]}$. This prompted neurologists to treat these patients by suppressing their immune systems, which ultimately combated their seizure frequency and severity ${ }^{[2]}$. It is worth noting that historically, neural autoantibodies are detected in only $30 \%$ of patients and good clinical reasoning is needed to determine if a patient is eligible for detailed neural testing ${ }^{[2]}$. This judgment is necessary, since seropositive results may lead to uncertain significance ${ }^{[2]}$. While the true prevalence of $\mathrm{AE}$ is unknown, it is suspected that between $14 \%$ and $20 \%$ of patients with refractory epilepsy of unknown etiology can be attributed to an immune basis and as much as a third of patients do not benefit when current symptomatic epilepsy management strategies are used $^{[2,5-7]}$.

It has been demonstrated that $\mathrm{AE}$ does not respond well to conventional antiepileptic treatment but may respond better to targeted immunotherapies in combination with $\mathrm{AEDs}^{[8]}$. According to the literature, within 4-6 weeks, many patients who are treated with immunotherapy display improved outcomes ${ }^{[2]}$. By highlighting important special characteristics of patients with AE, earlier identification of an underlying autoimmune etiology may be achieved. In light of the benefits that early immunotherapy has to offer patients with refractory epilepsy, it is important to emphasize that an autoimmune etiology should be considered during initial investigations to initiate immunotherapy promptly when appropriate ${ }^{[\rho]}$.

To provide context, in recent years, literature reporting on biomarkers in the field of epilepsy has resulted in approximately 30 publications ${ }^{[4]}$. It has been noted that due to the variable prognoses and various classifications within epilepsy, the design of most studies focuses on differentiating the epilepsy population $^{[4]}$. While an appropriate approach, this means that many of these populations under study are small in number, difficult to replicate, and therefore lack specificity. Additionally, it is difficult to compare clinical data as the etiology-dependency of biomarkers and their specificity to epilepsy has not been strategically analyzed ${ }^{[4]}$. This lack of specificity is particularly important in relation to AE as differential diagnoses are common.

A majority of the information we have about $\mathrm{AE}$ and seizure generation is derived from the discovery of neural autoantibodies. While not well understood, recent clinical and experimental studies relating to these autoantibodies have contributed to the understanding of their roles and have aided in the mitigation of disease progression. These roles have been determined in which modification of these targets through immunotherapy as a replacement/addendum to standard epilepsy therapies have been associated with reduced epileptogenesis ${ }^{[1]}$.

This review attempts to summarize the current understanding of autoantibodies that have been associated with AE. For more comprehensive completion, this review explores their potential as diagnostic tools, their roles in disease activity, and their implications in the development of preventive intervention strategies and effective immunotherapies ${ }^{[10]}$. 


\section{NEURAL AUTOANTIBODIES}

Neural autoantibodies disrupt surface proteins and cause functional modifications that are pathologically implicated in epileptogenesis and a myriad of clinical phenotypes ${ }^{[1]}$. While less recognized, neural autoantibodies have shown correlation with cancers and solid tumors ${ }^{[1]}$.

\section{Alpha-amino-3-hydroxy-5-methyl-4-isoxazolepropionic acid receptor antibodies}

Alpha-amino-3-hydroxy-5-methyl-4-isoxazolepropionic acid receptor (AMPAR) is a subtype of glutamate receptors that underlies the mechanisms responsible for the fast impulse-conducting neurotransmission in the brain that is important for synaptic plasticity and expression of long-term potentiation ${ }^{[11-13]}$. AMPAR antibodies have been classically noted most prominently in those presenting with motor deficits along with distinctive LE, limbic encephalopathy, bipolar psychosis, and pathologic tumors ${ }^{[12]}$. From the literature, the anti-AMPAR patient population features a considerable range of clinical manifestations, thereby conferring substantial practical difficulties in creating diagnostic guidelines ${ }^{[14]}$.

For example, in a case series evaluating the clinical spectrum related to AMPA, patients who had AMPAR antibodies in both their serum and CSF samples had similar acute conditions. The most prominent clinical features include confusion, isolated epileptic seizures, isolated amnestic episodes, and severe forms of fulminant encephalitis ${ }^{[15]}$. Other frequent features include alterations in cognitive functions, namely memory deficits, and disruptions of executive function ${ }^{[15]}$. Less frequent features include sleep disorders, cerebellar signs, nystagmus, fever, aphasia, and headache ${ }^{[15]}$. This clinical spectrum highlights the diverse clinical presentations in AE patient populations.

Fortunately, this affected patient population is highly treatable due to the well-documented reversal of effects with the removal of AMPAR antibodies and administered immunomodulation ${ }^{[11,14]}$. While the age of the affected population varies across the literature, the average is 60 years with a bias towards middle-aged women ${ }^{[11-15]}$. It is important to administer treatments in a prolonged and timely manner to prevent long-term disability as relapses are known to be frequent ${ }^{[11,12,15]}$.

To identify and quantify these cell surface antigens, clinical antibody testing such as immunoprecipitation, immunohistochemistry, Western blot (specific to glutamate subunits GluR1/2 heteromers), enzyme-linked immunosorbent assay, and mass spectrometry are used to produce immunolabeling of the cell surface and neuronal processes ${ }^{[11,14,15]}$. Characterization of patients' antigens derived from their cerebrospinal fluid (CSF) can be revealed by observing their effects on neuronal cultures and cell-based assays coded for GluR1/2 genes $^{[11,14,15]}$. Another more recent characterization method uses bacterial fusion proteins composed of the amino-terminal domain of GluR $1 / 2^{[14]}$. These analyses allow for visual distribution of target antigens along dendrites in a punctuated manner ${ }^{[1,14,15]}$. Importantly, AMPAR antibodies are commonly found accompanied by high lymphocyte count, high protein level, and the presence of oligoclonal bands in the $\mathrm{CSF}^{[11,2]}$. Despite this plethora of testing modalities, serum AMPAR antibody levels may initially be negative, but it does not rule out an AE diagnosis ${ }^{[12]}$.

In terms of its mechanisms, recent studies have shown that patient anti-AMPAR antibodies are characterized by a decrease in the total surface protein level and synaptic localization of AMPARs through increased internalization and degradation ${ }^{[13]}$. In conjunction with this process is the accumulation of internalized AMPAR clusters that cause dysfunctional action potentials ${ }^{[13]}$. In determining whether this accumulation affects AMPAR-mediated neurotransmission, measurement recordings from neurons treated with patient CSF were carried out in the presence of NMDAR-mediated currents ${ }^{[13]}$. Results demonstrated that these antibodies only affected synaptic AMPAR-mediated currents, which is consistent with the functional weakening effect of glutamatergic synaptic transmission due to the effect of localized AMPAR clusters ${ }^{[13]}$. This finding supports the differing clinical phenotypes associated with each antibody ${ }^{[11,13]}$. For example, those 
with anti-AMPAR encephalitis do not develop involuntary dyskinesias, whereas those with anti-NMDAR encephalitis do ${ }^{[11,12]}$.

Of interest, the presence of anti-LGI1 and anti-GAD65 antibodies in addition to anti-AMPAR antibodies shows distinct presentations that are both associated with hippocampal atrophy ${ }^{[16,17]}$. Anti-LGI1 antibodies are associated with more severe symptoms and significantly poorer verbal and figural memory outcomes, which suggests permanent functional damage ${ }^{[17]}$. The frequent development of these adverse events suggests that it is particularly important for patients to be identified and treated quickly ${ }^{[17]}$. On the other hand, antiGAD65 antibodies are also associated with cerebellar ataxia ${ }^{[16]}$. Altogether, these autoantibodies may result in significant cognitive alterations that are secondary to subclinical seizures. However, even when antineuronal autoantibodies are detected in a patient, the origin may not be autoimmune in nature, and the importance of detecting AMPAR must be based on both the clinical context and the exclusion of differential diagnoses ${ }^{[17]}$.

\section{VGKC-complex antibodies: LGI1 \& contactin-associated protein-like 2}

Voltage-gated potassium channel (VGKC) complex antibodies are closely related to AE and refractory seizure disorders due to their important roles in the generation of neuronal action potentials ${ }^{[6,18,19]}$. VGKC complex autoimmunity was first reported in patients with neuromyotonia ${ }^{[20]}$, Morvan syndrome ${ }^{[21-23]}$, and limbic encephalitis ${ }^{[24,25]}$. These conditions are characterized by nervous system dysfunction and a myriad of resulting clinical symptoms. In terms of treatment, plasma exchange and immunomodulatory therapies have shown good results in reducing VGKC antibody levels and in subsequently improving symptoms ${ }^{[22]}$.

EEG in patients with AE often shows abnormalities that may be attributed to several possible causes such as generalized background slowing or multiple independent spike foci ${ }^{[18]}$. Brain magnetic resonance imaging (MRI) in patients may be abnormal with T2 hyperintensity, and restricted diffusion of the medial temporal lobe $e^{[26]}$. In particular, medial temporal swelling and fluid-attenuated inversion recovery (FLAIR) hyperintensity is frequently observed shortly after onset of epileptic activity and can persist on MRI for months ${ }^{[18,26]}$. On the other hand, while cortical diffusion-weighted imaging hyperintensity can be found, it frequently resolves with seizure relief ${ }^{[27]}$.

These VGKC-associated proteins, both of which have extracellular plasma membrane components, are known to be the targets of the antibodies, rather than the VGKC complex ${ }^{[20-22]}$. To differentiate the two proteins, LGI1 antibodies are predominantly found in patients without tumors with limbic encephalitis or epilepsy, whereas antibodies to contactin-associated protein-like 2 (CASPR2) are more commonly found in patients with peripheral nervous system manifestations, limbic encephalitis, Morvan syndrome or neuromyotonia ${ }^{[24,28]}$. It has been noted that mutations in genes encoding these proteins often run in families, reinforcing the notion that genetic and autoimmune conditions are inextricably linked ${ }^{[28]}$.

\section{LGI1 antibodies}

LGI1 is a neuronal protein that binds to presynaptic disintegrin and metallopeptidase protein 23 (ADAM23) and postsynaptic ADAM22 ${ }^{[29]}$. This binding allows for fast neurotransmission and enables long-term synaptic plasticity ${ }^{[29]}$. Once transfected with either protein, a uniform distribution of LGI1 in the cytoplasm is achieved and the reactivity of patients' serum and CSF is robust ${ }^{[28]}$. These findings have provided the foundation for an objective diagnostic test ${ }^{[28]}$.

The LGI1 gene was originally found through positional cloning using a glioma cell line in the late $1990 \mathrm{~s}^{[30]}$. Since its discovery, research has suggested its role in tumor invasion and as a potential metastasis suppressor gene $^{[31,32]}$. It has also been implicated as a key player in autosomal dominant lateral temporal lobe epilepsy due to mutations in the LGI1 gene, which disrupts the protein's structural integrity and therefore its involvement in protein-protein binding ${ }^{[33-38]}$. 
Limbic encephalitis and Morvan syndrome are the most noted clinical features of anti-LGI1 autoimmunity ${ }^{[1,6,28,39]}$. Anti-LGI1 encephalitis is predominantly found in older men (64\%), with a median of around 62 years, and is commonly associated with other cancers ${ }^{[28,39,40]}$. Typical limbic encephalitis presentations include seizures $(53 \%)$ and cognitive disorders $(42 \%)^{[39]}$, with a majority of patients developing memory impairment or behavioral changes ${ }^{[39]}$. Other common symptoms include amnesia, confusion, spatial disorientation, autonomic dysfunction, hallucinations, insomnia, hypersomnolence, and sleep disturbances ${ }^{[39,40]}$.

With regard to data derived from videos and still images of patients with antibodies to LGI1, many patients experience faciobrachial dystonic seizures (FBDS) which primarily affect the arm and ipsilateral face ${ }^{[40]}$. To provide context, FBDSs occur in $47 \%$ of patients with anti-LGI1 encephalitis ${ }^{[39]}$ and $43 \%$ of patients with anti-LGI1-associated $\mathrm{AE}^{[1]}$. It is important that these associations are highlighted as they are often misdiagnosed as other movement or psychogenic disorders ${ }^{[41]}$. FBDSs are characterized by brief contractions lasting between 3 and $15 \mathrm{~s}, 30-50$ times daily, of the face, arm, and leg ${ }^{[39-42]}$. Dystonic seizures are commonly triggered by a sensory aura such as emotions or movements, and are followed up by loss of awareness, dysphasia, automatisms, agitation, and speech arrest ${ }^{[40-42]}$. The difficulty in accurate diagnosis lies in part in the fact that FBDSs may present as isolated incidents prior to the onset of the more classically known symptoms of encephalitis by as much as 5 weeks ${ }^{[39,40]}$ and often does not respond to AEDs alone ${ }^{[40,41]}$.

A well-established treatment for FBDS includes corticosteroids, with seizure cessation mostly observed within 2 months ${ }^{[39-41]}$. Unfortunately, while seizures improve, cognitive dysfunction is more long-lasting and persists for months or even years ${ }^{[39,41]}$. AEDs generally do not improve symptoms and cause severe cutaneous reactions in around $41 \%-50 \%$ of patients ${ }^{[40]}$. Such reported AEDs include phenytoin, carbamazepine, valproate, lamotrigine, and levetiracetam ${ }^{[40]}$. On the other hand, immunotherapies often produce dramatic improvements ${ }^{[40]}$. It is important to note that evidence suggests that 1 in 3 patients progress to develop further clinical relapses despite immunotherapy, and a high frequency of seizures may be observed despite treatment with both AEDs and immunotherapies ${ }^{[39,41]}$.

Principally, many patients with LGI1-antibody encephalitis experience frequent multifocal seizure localizations with multiple semiologies, FBDS, and thermal sensations ${ }^{[42]}$. They also develop other generalized non-dystonic seizure types ${ }^{[1,40,42]}$. Subclinical electrographic seizures are not infrequent ${ }^{[3,42]}$. Others show abnormalities such as bilateral and unilateral medial temporal lobe high T2 signal change, high signal in the right caudate/putamen, and hippocampal/caudate atrophy ${ }^{[1,39,40]}$. However, some patients have normal brain MRI, most notably during the early stages of the disease when only FBDSs are clinically relevant ${ }^{[2]}$. While the CSF is often unremarkable, serum hyponatremia is a useful clue of LGI1 autoimmunity, which occurs in about $66 \%$ of patients at different stages of their disease ${ }^{[2]}$. Therefore, it is recommended that several serum sodium measurements are taken throughout patient care ${ }^{[40]}$.

These findings suggest that these diverse combinations of clinical and electrical symptoms should alert providers to the possibility of underlying LGI 1 -antibodies ${ }^{[43]}$.

\section{CASPR2 antibodies}

CASPR2, a transmembrane protein expressed in both the central and peripheral nervous systems, plays a critical role in proper localization of VGKCs and the regulation of axonal excitability ${ }^{[28,44,45]}$. The deletion or mutations of contactin associated protein 2 gene (CNTNAP2), the human gene that encodes CASPR2, are associated with seizures, peripheral neuropathy, autism, dysplasia, and schizophrenia ${ }^{[45-49]}$. The symptoms are a result of the disruption of inhibitory interneuron activity ${ }^{[50]}$. The median age of patients at symptom onset is in the sixties and historically affects males more frequently than females ${ }^{[5]}$. Median time to nadir of disease is around 4-6 months, but the time has ranged from 10 days to 9 years ${ }^{[51]}$. 
While epilepsy is the main symptom that prompts patients to seek medical attention, growing evidence suggests that the CASPR2 antibody may be associated with $\mathrm{AE}^{[1,6,52]}$. Recurrent seizures including focal seizures, generalized seizures, and nonconvulsive status epilepticus ${ }^{[45,53]}$ are the predominant clinical manifestations, with the most common presenting symptoms being cognitive disturbance, anterograde and episodic memory disorders, psychiatric symptoms such as depressed moods or persecutory thoughts, and pain ${ }^{[51,52,54]}$. The type of pain most frequently reported is neuropathic, usually described as a burning sensation in the hands or feet; other types of pain include joint and muscle pain, chest pain, and lumbocoxalgia ${ }^{[51]}$. In addition to cerebral symptoms, also common are sleep disorder, nausea, palpitations, epigastric aura, flushing, pilomotor erection, weight loss, autonomic dysfunction, and cerebellar symptoms ${ }^{[51,55]}$.

Unlike the patients previously discussed in the LGI1 portion of this review, patients who are positive for CASPR2 antibodies do not exhibit FBDS ${ }^{[53]}$. Furthermore, distinctive symptoms associated with the CNS are not hallmarks in patients with CASPR2 antibodies (40\%) compared to those with LGI1 antibodies $(85.7 \%)^{[56]}$. Notably, immunoglobulin G4 subclass antibodies are consistently present in patients and many are also positive for immunoglobulin $\mathrm{G} 1$ antibodies ${ }^{[1,52]}$. Lastly, serum hyponatremia is not a feature of patients with CASPR2 antibodies, whereas it is frequently identified in LGI1 antibody-positive patients ${ }^{[53]}$.

CSF profiles are normal in 50\%-75\% of the patient population ${ }^{[51,52]}$. Abnormal CSF profiles have shown mild pleocytosis, ranging from 6-20 cells $/ \mathrm{mL}^{[1,53]}$. In particular, CSF antibody positivity has been shown to be predictive of autoimmune encephalitis, where the main symptoms are seizures and cognitive changes ${ }^{[52]}$. On the other hand, patients with negative CSF but serum positivity tend to present with Morvan syndrome with a higher incidence of thymoma ${ }^{[52]}$.

While neuropathic pain is often reported, it is not uncommon for patients to have unremarkable nerve conduction studies $^{[51]}$. In patients with cognitive decline or seizures, $70 \%$ have unremarkable MRI, while $24 \%$ show bilateral T2 hyperintensity of the medial temporal lobes and diffuse meningeal enhancement ${ }^{[51]}$. Abnormal EEG recordings such as epileptiform discharges are quite $\operatorname{common}^{[53]}$, and brain positron emission tomography scans are often pathological ${ }^{[52]}$.

Typical treatments include IV immunoglobulin, IV or oral steroids, and plasma exchange ${ }^{[51]}$. Less common treatments include azathioprine and second-line immunotherapy (cyclophosphamide or rituximab) ${ }^{[51]}$. If tumors are present, surgery or chemotherapy is useful to improve treatment response. The beneficial responses to immunotherapy suggest that mutation of the CASPR2 gene plays a pathogenic role ${ }^{[46]}$.

Treatment response occurs in a majority (>90\%) of patients with $25 \%-30 \%$ experiencing clinical relapses, some of which occur up to 7 years after the initial episode of the disease, and may involve different parts of the nervous system than those involved in the initial episode $e^{[51,57]}$. These late relapses of some patients may suggest an even higher relapse rate ${ }^{[51]}$. Furthermore, in almost half of the cases with relapses, the initial diagnosis of the disease was made during the relapse, suggesting that patients with a monophasic disease may be missed at disease onset, leading to an overestimation of relapse rates ${ }^{[51]}$. CASPR2 antibody-associated epilepsy in particular responds well to immunotherapy with full $(39 \%)$ or partial recovery $(52 \%)^{[45,51]}$.

Due to the complex co-occurrence of other autoantibodies which may be mistaken for a motor neuron disorder, the diagnosis of patients with CASPR2 antibodies is often more complicated than that of patients with classical limbic encephalitis and LGI1 antibodies ${ }^{[45]}$.

\section{DPPX antibodies}

DPP6 or DPPX is a cell surface auxiliary subunit of the Kv4.2 potassium channel ${ }^{[57]}$. The function and expression of DPPX is seen in the hippocampus, cerebellum, striatum and myenteric plexus, as seen in anti- 
DPPX encephalitis ${ }^{[58,59]}$. Serum and CSF are equally sensitive for detecting DPPX to make the diagnosis of anti-DPPX encephalitis ${ }^{[60]}$.

Immunocytochemical characterization of the binding pattern in murine hippocampal neurons illustrated somatodendritic perisynaptic localization in glutamatergic and GABAergic synapses and a close colocalization with KV4.2, which is consistent with the finding of DPPX being an auxiliary subunit of Kv $4.2^{[59]}$. With the following three sets of experiments, DPPX was identified: immunoprecipitation from cultures of dissociated rat hippocampal neurons, immunostaining from a cell-based assay and comparative brain immunostaining of wild-type and $D P P X$-null mice ${ }^{[57]}$.

The primary study initially set out to report the clinical and immunological characteristics of four patients with marked neuropsychiatric symptoms and antibodies against DPPX ${ }^{[57]}$. The main symptoms of DPPX encephalitis were characterized as agitation, myoclonus, tremor and seizures ${ }^{[57,59]}$. These symptoms are congruent with neuronal hyperexcitability and similar with increased excitability noted in electrophysiological studies of DPPX knockout mice. These findings suggest that genetic or immunologic alteration of the DPPX-Kv4.2 complex causes neuronal hyperexcitability ${ }^{[57]}$. Downregulation of DPPX and Kv4.2 by anti-DPPX serum is expected to result in CNS hyperexcitability, which is suspected to be the underlying cause of the neurologic manifestations of anti-DPPX encephalitis ${ }^{[59]}$. Patients with DPPX encephalitis have been reported to experience subacute development of cognitive dysfunction, agitation, hallucinations, confusion, resting tremor and myoclonus ${ }^{[57,61]}$.

Diarrhea and weight loss often precede and overlap with neurological symptoms ${ }^{[57,61]}$. The diarrhea is severe, can last for weeks and begins concurrently with the initial episode of encephalitis. This suggests an autoimmune etiology associated with diarrhea and DPPX antibody-associated encephalitis. Through multiple studies, it was discovered that there is a potent expression of DPPX by myenteric plexus neurons, thus supporting the theory that patients' antibodies may alter the function of the plexus, thereby resulting in gastrointestinal hyperactivity ${ }^{[57,59,60,62]}$. Studies in guinea pigs and human myenteric plexus preparation showed signs of increased activity of enteric neurons, likely due to immediate modulation of electrophysiologic properties of gastrointestinal DPPX-Kv4.2 complexes upon binding of anti-DPPX antibodies to their antigenic target ${ }^{[59]}$. Associated weight loss is also not subtle (median of $20 \mathrm{~kg}$ per patient) and is one of the first symptoms of the disease ${ }^{[63]}$. However, gastrointestinal hypomotility has also been recognized in cases, suggesting that anti-DPPX antibodies could lead to the loss or exhaustion of enteric neurons in more chronic stages of the disease $e^{[59,60,62]}$.

Another noteworthy feature of DPPX encephalitis patients was the development of transient hypersomnia and sleep disturbances, including insomnia, limb movements, and disrupted REM sleep ${ }^{[5,60]}$. The detection of DPPX IgG as part of the patient's neurologic diagnosis in two patients additionally led to the oncologic diagnosis of B cell lymphoma ${ }^{[60]}$. Additional symptoms found in patients with anti-DPPX encephalitis include exaggerated startle response and CSF pleocytosis ${ }^{[6]]}$. Progressive encephalomyelitis with rigidity and myoclonus (PERM) has additionally been identified in 3 patients positive for anti-DPPX antibodies. This group was noted to be a specific variant of PERM consisting of marked hyperekplexia, cerebellar ataxia and trunk stiffness. Hyperekplexia in these patients was associated with startle reflexes to tactile, acoustic and visual stimulation with short response latencies in the neck muscles. Cerebellar ataxia included a full range of cerebellar eye movement disorders, with less severity in the trunk and legs. High titers of new DPPX antibodies were detected in the serum and CSF of these patients ${ }^{[62]}$.

Patients' purified IgG and serum reduced the expression of DPPX in membranes of hippocampal neurons, which was associated with a similar reduction of Kv4.2. Since DPPX enhances cell surface expression of Kv4.2, it is likely that anti-DPPX antibodies interfere with DPPX-mediated membrane targeting of Kv4.2 ${ }^{[59]}$. 
Regarding treatment, it is recommended that patients with even mild neurologic or psychiatric symptoms with prodromal diarrhea be worked up for the determination of DPPX antibodies and immunotherapy promptly started if appropriate ${ }^{[57,59]}$. Several studies have shown that patients respond well to immunotherapy ${ }^{[57,59,63]}$. Patients who received early and sustained immunotherapies improved neurologically; however, most patients subsequently relapse or need a prolonged course of immunotherapy, consisting of high dose IVIG, plasma exchange, rituximab or cyclophosphamide ${ }^{[60,61,64]}$. It is suggested that patients with anti-DPPX encephalitis be initially treated with glucocorticoids, and if they are responsive, moderate immunosuppression with azathioprine is then added during the glucocorticoid taper ${ }^{[64]}$.

\section{GABA $_{A} R$ antibodies}

In 2014, Petit-Pedrol et al ${ }^{[65]}$ sought to report the clinical characteristics of a new epileptic disorder and to identify the target antigen and effects of patients' antibodies on neuronal cultures. This was an observational study in which serum and CSF samples were obtained from 140 patients with symptoms of encephalitis, seizures or status epilepticus and antibodies to previously identified neuropil antigens. The $\mathrm{GABA}_{\mathrm{A}}$ receptor antibody is correlated with a severe form of encephalitis ${ }^{[65]}$. $\mathrm{GABA}_{\mathrm{A}}$ receptor autoantibodies are associated with autoimmune encephalitis, and in particular, the downregulation of the receptor function results in seizure activity ${ }^{[65,66]}$. MRI findings in this disorder comprise multifocal and cortical-subcortical MRI T2/FLAIR hyperintensities. These findings on imaging should increase suspicion of $\mathrm{GABA}_{\mathrm{A}}$ receptor encephalitis, since they are rarely seen in other autoimmune encephalitis disorders ${ }^{[65-67]}$.

Altered behavior, cognitive impairment, decreased consciousness and movement disorders are many of the most common associated symptoms ${ }^{[65,67]}$. Patients can also present as postviral encephalitis or coincide with other autoantibodies, including GAD65, NMDAR and $\mathrm{GABA}_{\mathrm{B}} \mathrm{R}^{[66]}$. Spatola et al ${ }^{[67]}$ confirmed that seizures are the most frequent manifestation of $\mathrm{GABA}_{\mathrm{A}}$ receptor encephalitis, where $88 \%$ of patients had seizures, usually at presentation and frequently accompanied by status epilepticus that often required a pharmacologically induced coma. There is additionally a paraneoplastic subtype of encephalitis associated with invasive thymoma in which $\mathrm{GABA}_{\mathrm{A}}$ receptor autoantibodies coexist with LGI1, CASPR2 or DCC antibodies $^{[66]}$.

$\mathrm{GABA}_{\mathrm{A}}$ receptor is a ligand-gated pentameric chloride channel that mediates fast inhibitory transmission ${ }^{[68]}$. Impaired $\mathrm{GABA}_{\mathrm{A}}$ receptor-mediated inhibition is an important pathophysiologic mechanism of increased neuronal excitability leading to seizures ${ }^{[68]}$. Mutations within the $\mathrm{GABA}_{\mathrm{A}}$ receptor gene carry an increased epilepsy risk ${ }^{[6,70]}$. There are two loss of function mutations that are linked to different forms of idiopathic generalized epilepsy, GABRG2 (encoding gamma 2 subunit) and GABRA1 (encoding alpha1 subunit) ${ }^{[68]}$. Patients were found to have increased serum titers and CSF antibodies against GABA receptors with encephalitis and refractory seizures or status epilepticus, many of whom needed pharmacologically induced coma $^{[65]}$. The identification of this disorder may be difficult, since the development of seizures is rapid and since there may be coexisting autoimmune disorders. $\mathrm{GABA}_{\mathrm{A}}$ receptor antibodies were shown to react with alpha1, beta3 or both subunits ${ }^{[65]}$. The alpha1 subunit always recognized the patients' CSF $^{[65]}$. Most patients had an abnormal EEG with multifocal seizures and generalized periodic discharges in two cases, associated with high serum antibody titers and extensive cortical and subcortical brain MRI abnormalities ${ }^{[65]}$. Patients were additionally identified to have malignant thymoma and encephalitis, seizures, and multifocal cortical FLAIR MRI irregularities. Patients with encephalitis and low serum titers of antibodies and absent CSF antibodies had developed seizures, including the youngest patient, a 2-year-old, who required pharmacologically induced coma for status epilepticus ${ }^{[65]}$.

It is additionally recommended that patients with encephalitis or seizures associated with GAD65 antibodies be evaluated for antibodies to $\mathrm{GABA}_{\mathrm{A}}$ receptors ${ }^{[65]}$. 
Through immunotherapy, symptomatic therapy or prolonged intensive care support, most patients had partial or complete resolution of $\mathrm{GABA}_{\mathrm{A}}$ receptor-associated encephalitis ${ }^{[65,66]}$.

\section{GABA $_{B} R$ antibodies}

Since several encephalitis and seizure disorders that were once thought to be idiopathic were discovered to be immune-mediated, Lancaster et al. ${ }^{[71]}$ studied patients thought to have paraneoplastic or immunemediated limbic encephalitis to determine which autoantigen was involved. $\mathrm{GABA}_{\mathrm{B}}$ antibodies were correlated with limbic encephalitis and small cell lung cancer $(\mathrm{SCLC})^{[71-73]}$. $\mathrm{GABA}_{\mathrm{B}}$ receptor antibodies are encountered rarely in serologic evaluation for evidence of paraneoplastic neurologic autoimmunity, but it is clinically significant when detected ${ }^{[74]}$. Cell-based assay of both serum and CSF have antibodies that react with $\mathrm{GABA}_{\mathrm{B}} 1$ and $\mathrm{GABA}_{\mathrm{B}} 2$ and can be used for detection of the antibody ${ }^{[7]]}$. Patients presented with early or marked seizures, memory deficiencies, elevated anxiety and mood dysregulation ${ }^{[7]}$. MRI and EEG had findings consistent with predominant limbic dysfunction ${ }^{[71]}$. Additional symptoms of $\mathrm{GABA}_{\mathrm{B}}$ antibody receptor LE include memory loss, confusion, hallucinations, personality changes, and seizures, found to be difficult to control in 1 patient ${ }^{[72]}$. Patients also developed autonomic dysfunction and hypoventilation, mild limb spasticity and marked psychiatric symptoms ${ }^{[72]}$. Novel symptom presentation was observed in 2 patients who developed ataxia and opsoclonus ${ }^{[72]}$. It is also noted that $\mathrm{GABA}_{\mathrm{B}}$ receptor antibodies occurred in patients with neurologic dysfunction with or without SCLC but not in cancer patients without neurologic symptoms.

$\mathrm{GABA}_{\mathrm{B}}$ receptor antibody encephalitis is closely correlated with $\mathrm{SCLC}^{[71,72]}$. About half of patients with underlying SCLC were identified after the development of neurologic symptoms ${ }^{[72]}$. Melanoma and thymus cancer were also associated with $\mathrm{GABA}_{\mathrm{B}}$ receptor antibody $\mathrm{LE}^{[72]}$. As all of these tumors are derived from the neuroectoderm, they likely are able to express $\mathrm{GABA}_{\mathrm{B}}$ receptors ${ }^{[72]}$. One patient with GAD65 antibodies and $\mathrm{GABA}_{\mathrm{B}}$ receptor antibodies without $\mathrm{LE}$ had reversible ataxia associated with carcinoid of the thymus ${ }^{[73]}$. Patients with high titers of $\mathrm{GABA}_{B}$ receptor antibodies usually present with an isolated LE in the setting of SCLC $^{[74]}$. Low titers of $\mathrm{GABA}_{\mathrm{B}}$ receptor IgG coexisted with high titers of paraneoplastic neuronal nuclear and cytoplasmic antibodies (including ANNA-1, ANNA-3 and CRMP-5 IgG) ${ }^{[74]}$. All patients with LE and SCLC who were previously considered seronegative for onconeural antibodies were found to have antibodies

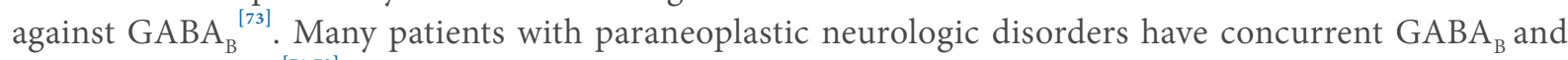
GAD65 antibodies ${ }^{[7,73]}$. Thus, it is suggested to routinely look for $\mathrm{GABA}_{\mathrm{B}}$ receptor antibodies in all patients with LE suspected to be GAD65 antibody related ${ }^{[73]}$.

Immunoprecipitation and mass spectrometry showed antibodies which recognized B1 subunits of the $\mathrm{GABA}_{\mathrm{B}}$ receptor, an inhibitory receptor associated with seizures and memory recognition function when disordered $^{[71]}$. $\mathrm{GABA}_{\mathrm{B}}$ receptors mediate presynaptic inhibition by activating $\mathrm{G}$ protein coupled inward rectifying potassium channels and through the inhibition of calcium channels ${ }^{[71]}$. Low levels of $\mathrm{GABA}_{\mathrm{B}}$ receptor IgG was also detected in some patients with non-encephalitis paraneoplastic neurologic disorders ${ }^{[71]}$.

$\mathrm{GABA}_{\mathrm{B}}$ is expressed widely throughout the brain, with the highest levels detected in the hippocampus, thalamus and cerebellum ${ }^{[71,75,76]}$. On the basis of MRI and EEG findings, in $\mathrm{GABA}_{\mathrm{B}}$ receptor antibody LE, the hippocampus and temporal lobes are the most affected ${ }^{[7]]}$.

Patients with $\mathrm{GABA}_{\mathrm{B}}$ receptor antibody LE respond well to immunotherapy ${ }^{[72,74]}$. However, survival may be limited due to tumor progression or complications of chemotherapy ${ }^{[72]}$.

\section{GFAP antibodies}

The role of antibodies to glial fibrillary acidic protein (GFAP) in AE patients was first described in detail by Fang et al. ${ }^{[77]}$ in 2016. The study described 16 patients who developed meningoencephalomyelitis and exhibited an antibody to a cytosolic intermediate filament protein of astrocytes ${ }^{[77]}$. This was 
later demonstrated to be IgG which colocalizes to the alpha and delta isoform of GFAP intermediate filament ${ }^{[77]}$. The intracellular location of GFAP makes it inaccessible to circulating antibodies and hints at a nonpathogenic role as a mere marker of T cell-mediated autoimmune response ${ }^{[78]}$. Histopathological findings from biopsies of patients with GFAP antibodies have hinted at this mechanism, with leptomeningeal biopsy in one patient revealing a necrotizing, inflammatory infiltrate containing CD8+ lymphocytes, macrophages, and multi-nucleated giant cells ${ }^{[7]}$. The most common clinical manifestations include meningoencephalitis or encephalitis, encephalopathy, myelitic symptoms, vision changes and headache ${ }^{[77-79]}$. Other common findings include optic disc edema without elevated increased intracranial pressure, tremor, progressive cognitive impairment, myelopathy, autonomic instability, ataxia, psychiatric symptoms, treatment-resistant epilepsy, and movement disorder ${ }^{[77-79]}$. Up to $8 \%$ of patients may have a peripheral nervous system disorder such as neuropathy or myasthenia gravis ${ }^{[77]}$. Around $30 \%$ of patients present initially with prodromal symptoms such as fever, dengue fever, interstitial pneumonia or chronic severe diarrhea, which subsides with immunotherapy ${ }^{[78,79]}$. Patients may also have additional autoimmune findings such as type 1 diabetes (T1D), Grave's thyroiditis, rheumatoid arthritis, ulcerative colitis, or psoriatic arthritis ${ }^{[78]}$. Around $1 / 3$ of patients studied had an associated neoplasm: the most common being ovarian teratoma, carcinoid (admixed with teratoma), salivary pleomorphic adenoma, prostate carcinoma, and melanoma ${ }^{[77,79]}$. Coexisting autoantibodies are present in up to $40 \%$ of patients, the most common being NMDAR IgG and AQP4-IgG ${ }^{[77]}$.

GFAP antibodies can be detected by indirect immunofluorescence ${ }^{[77-79]}$. CSF testing tends to be more sensitive than serum ${ }^{[79]}$. Immunostaining in mouse brains was found in pia, sub-pia, mid-brain foci, periventricular region, and rostral migratory stream ${ }^{[77]}$. Enteric ganglia and mucosa penetrating nerves stained positive in the periphery ${ }^{[77]}$.

Brain MRI may show diffuse T2 abnormalities in periventricular white matter ${ }^{[77]}$. Linear perivascular radial enhancement is often a prominent feature ${ }^{[77,79]}$, and $22 \%-33 \%$ of patients may have leptomeningeal enhancement ${ }^{[77,79]}$. CSF very often shows inflammatory signs, namely pleocytosis, elevated protein, hypoglycorrhachia, and oligoclonal bands ${ }^{[77-79]}$. Development of meningoencephalomyelitis does not seem to be correlated with antibody titer level ${ }^{[79]}$.

Most patients respond well to initial treatment with immunotherapy, but up to 64\% may relapse and require additional therapy ${ }^{[7]]}$. Patients refractory to initial treatment have been trialed on IV methylprednisolone, IVIG, and plasma exchange. Long-term immunosuppression may be necessary in some cases to gain control of symptoms ${ }^{[78]}$.

\section{Antibodies to glycine receptors}

Glycine receptor (GlyR) antibodies were first described in a case study by Hutchinson et al ${ }^{[80]}$ in 2008 , which described a patient with progressive encephalomyelitis, rigidity, and myoclonus, a syndrome that later came to be known as PERM (after the clinical manifestations in the index case) ${ }^{[80,81]}$. GlyR antibodies have been demonstrated to be predominantly of the IgG1 subclass, which are able to activate complement on the surface of GlyR- $\alpha 1^{[82]}$.

In a recent case series with a literature review of 187 patients with antibodies targeting GlyR present in either serum or CSF, PERM and stiff person syndrome (SPS) were the most common clinical manifestations ( $47.6 \%$ of the total $)^{[81]}$. The next most common finding was AE (22.4\% of total), with the rest demonstrating a heterogeneous mix of cerebellar ataxia, movement disorders, demyelination, cognitive dysfunction, and many other findings ${ }^{[81]}$. Epilepsy is more common in younger patients (average age in epilepsy group: 27.1 years), with PERM/SPS manifesting more often in older patients (average age: 43.2$)^{[81]}$. Malignancy is more common in patients with PERM/SPS, with some patients found to have thymomas, marginal B-cell lymphoma, breast cancer, Hodgkin's lymphoma and SLC ${ }^{[81]}$. One-third of patients may have 
an accompanying autoimmune disorder ${ }^{[82]}$. Other clinical findings reported with GlyR antibodies include hemiballism/tics, muscle spasms, laryngeal dystonia, hyperekplexia, status epilepticus, and an unusual neurological syndrome with extensive weakness and persistent clonus ${ }^{[81-83]}$. The heterogeneity of these syndromes is thought to be caused by either local disruption of the blood-brain barrier, allowing entry of peripheral antibodies into specific regions of the brain, or antibodies specific to different glycine receptor types $^{[81]}$.

EEG or MRI are often abnormal in patients with epilepsy, but lack specific or pathognomonic findings ${ }^{[1,82]}$. In one recent cohort study of 45 patients with GlyR antibodies, 15/21 patients tested showed abnormal EEG (slow activity, focal epileptic findings, cortical disturbance), and 10/36 showed abnormal MRI (white matter lesions, atrophy, temporal lobe inflammation, small vessel disease, short or patchy lesions, longitudinally extensive lesion, or other FLAIR lesions $)^{[82]}$. Diagnosis of GlyR antibody disease is typically confirmed by detection of antibodies in serum or CSF. Antibody presence has been detected using immunofluorescencebased assay on human kidney cells modified to express GlyR1 tagged with green fluorescent protein ${ }^{[82]}$.

Immunotherapy is often remarkably successful in treating GlyR antibody disease. Treatment often starts with methyl prednisone, escalating to high-dose prednisolone, then IVIG and plasma exchange as necessary. Treatment often has to be repeated, and patients may be weaned off steroids slowly. Refractory disease may also be treated successfully with cyclophosphamide, rituximab, azathioprine, and mycophenolate ${ }^{[82]}$. Relapses may occur, but often with less severe symptoms, and may necessitate further treatment with immunotherapies.

\section{mGluR5 antibodies}

In 1982, Ian Carr, a physician, described his daughter's development of progressive loss of memory, depression, hallucinations and bizarre behavior before being diagnosed with and successfully treated for Hodgkin lymphoma ${ }^{[84]}$. Dr. Carr postulated that a "circulating neurotransmitter-like molecule secreted by the tumor" could have caused her symptoms, which later became known as Ophelia syndrome ${ }^{[84]}$. Since then, similar cases have been associated with antibodies to metabotropic glutamate receptor 5 (mGluR5). This receptor acts via calcium/IP3 signaling, modulates neuronal functions including long-term depression, and is active in behavioral learning, specifically in extinction of nonreinforced behaviors ${ }^{[85,86]}$. The epitope localizes to the extracellular receptor region, causing antibodies to bind to the surface of live neurons ${ }^{[84]}$. Antibodies are IgG1, IgG2, IgG3 or combined ${ }^{[84]}$.

In recent case studies, the average age of onset of symptoms is $29^{[87]}$. Patients may initially present with predominantly psychiatric symptoms (depression and personality change), or symptoms such as headache and nausea ${ }^{[84]}$. Patients may initially present with nonspecific prodromal symptoms such as upper respiratory infection or fever ${ }^{[87]}$. mGluR5 is strongly associated with Hodgkin lymphoma (5/11 patients in one case series), and may initially present with cervical lymphadenopathy ${ }^{[84,87]}$. Other manifestations include shortterm memory deficit, emotional lability, delusions, seizure manifesting as status epilepticus, myoclonic jerks, sleep dysfunction, and movement disorders ${ }^{[84,87]}$. In children, the most common movement disorders are dystonic postures and oculogyric crisis, while adults often have postural tremor or myoclonic jerks ${ }^{[87]}$. Peak of disease occurs at a median of two weeks after symptom onset, and $36 \%$ of patients eventually require intensive care ${ }^{[87]}$.

MRI may show increased T2 signal in the mesial temporal area ${ }^{[84]}$. CSF may show pleocytosis and increased protein ${ }^{[8,87]}$, and $50 \%$ of patients show abnormal EEG with focal or diffuse slowing, epileptiform discharges ${ }^{[87]}$. mGlurR5 antibody is detectable in serum and may be determined by immunohistochemistry of rat hippocampal neurons or HEK293 cells transfected with mGluR5-coding plasmid. Testing for mGluR5 is not included in commercially available panels, so it must be specifically ordered by the clinician ${ }^{[84,87]}$. 
Sedation for seizures is sometimes required, and antipsychotics for psychiatric symptoms as well ${ }^{[84]}$. Treatment of underlying cancer with chemotherapy, and immunotherapy as well is often effective in alleviating neurologic symptoms ${ }^{[84,87]}$. Patients may experience relapse of neurologic symptoms, which may herald a tumor relapse as well ${ }^{[87]}$.

\section{NMDAR antibodies}

The $\mathrm{N}$-methyl-D-aspartate receptor (NMDAR) is an ion channel receptor protein responsive to NMDA (from whence its name derives), glutamate, and either D-serine or glycine. It is thought to play an important part in synaptic plasticity and memory function ${ }^{[88]}$. Antibodies to NMDAR are typically associated with autoimmune encephalitis but can also present with epilepsy as the sole or dominant feature ${ }^{[1]}$. First reports of this condition came from Vitaliani et al. ${ }^{[89]}$ in 2005, who described a constellation of psychiatric symptoms, encephalitis, and hypoventilation in women who had ovarian teratoma as well as antibodies against a hippocampal antigen. The antigen was later determined to be the NMDA receptor.

Antibodies to NMDAR are associated with focal motor, complex focal seizures, refractory complex focal seizures, and generalized status epilepticus ${ }^{[90,91]}$. Anti-NMDAR encephalitis most commonly occurs in young women and is accompanied by a tumor in $58 \%$ of cases, most commonly ovarian teratoma (40\% of cases $)^{[00,91]}$. Seizure as the first symptom of NMDAR antibody encephalitis occurs more commonly in children, while adults more commonly present initially with psychiatric symptoms ${ }^{[92]}$.

Anti-NMDAR encephalitis often presents as a syndrome including psychiatric manifestations, memory loss, seizures, movement dysfunction, speech dysfunction, decreased alertness, autonomic disorder, and central hypoventilation ${ }^{[0,91]}$, and $90 \%$ of patients exhibit at least 4 of the above symptoms within 4 weeks of the beginning of symptoms ${ }^{[90,91]}$. EEG is often abnormal, and may show non-specific, slow, disorganized activity sometimes with electrographic seizures. One-third of patients with anti-NDMAR encephalitis exhibit a particular EEG pattern known as "extreme delta brush", which consists of rhythmic delta activity at $1-3 \mathrm{~Hz}$ with superimposed bursts of rhythmic $20-30 \mathrm{~Hz} \beta$ activity on each delta wave ${ }^{[93]}$. The name of this pattern comes from delta brush, an EEG pattern sometimes seen in premature infants ${ }^{[93]}$. Normal MRI is found in $50 \%$ of patients but may demonstrate limbic or extralimbic changes ${ }^{[93]}$. Diagnosis is confirmed by detection via immunofluorescence assay of IgG antibodies reactive to the GluN1 (NR1) subunit of the NMDA receptor ${ }^{[94]}$. Anti-NMDAR antibodies are detectable more easily in CSF than serum, and may be accompanied by increased lymphocyte count, normal or slightly increased protein, and oligoclonal bands specific to $\operatorname{CSF}^{[0,991]}$. Higher CSF antibody levels are associated with more severe symptoms ${ }^{[00,91]}$. Brain biopsy does not diagnose NMDAR encephalitis, and typically shows normal or non-specific findings ${ }^{[00,91]}$.

Immunotherapy with steroids, IVIG, and plasmapheresis is the mainstay of treatment for anti-NMDAR encephalitis ${ }^{\left[9_{2}\right]}$. Those who fail initial therapy may be treated with rituximab or cyclophosphamide ${ }^{[92]}$. Removal of tumor, if found, is also an important treatment measure, and can speed improvement and help prevent relapses ${ }^{[92]}$. Recovery is typically slow, and relapses may occur (12\% in one cohort study), but they are less likely with early initiation of treatment and removal of tumor ${ }^{[00,92]}$.

\section{Voltage-gated calcium channels of $\mathrm{P} / \mathrm{Q}$-type antibodies}

Voltage-gated calcium channels of P/Q-type (VGCC-P/Q) and N-type (VGCC-N) in motor nerve terminals are targeted by IgG antibodies in Lambert Eaton syndrome ${ }^{[95]}$. VGCC-P/Q antibodies are found in over $90 \%$ of non-immunosuppressed patients with Lambert-Eaton Syndrome (LES), and VGCC-N antibodies are found in almost 3/4 of paraneoplastic cases (and over 1/3 of non-paraneoplastic cases) ${ }^{[96]}$. Several neurologic syndromes associated with VGCC antibodies other than LES have also been described ${ }^{[95,97,98]}$.

Median age of onset of symptoms for patients afflicted by VGCC antibodies is 57 years ${ }^{[95]}$. Patients may present with a wide variety of different symptoms including encephalopathy, ataxia, seizures, myelopathy, 
neuropathy, neuromuscular junction disorder, and myopathy ${ }^{[95]}$. VGCC antibodies have also been reported in association with behavioral changes mimicking frontotemporal dementia ${ }^{[98]}$. Other antibodies may coexist such as those to GAD65, muscle AChR, VGKC-complex, or $\mathrm{NMDA}^{[95]}$. Only one pediatric case of VGCC antibody disease has been reported, with the patient presenting with confusion, aphasia, transient fever, headache, dizziness and memory deficit, who ultimately responded well to immunotherapy ${ }^{[97]}$. A fifth of patients $(21 \%)$ may have a history of neoplasm or neoplasia, detected later ${ }^{[95]}$. Tumors reported in associated with VGCC antibodies include SCLC, breast adenocarcinoma, lymphoma, and tonsillar carcinoma ${ }^{[95]}$.

Interestingly, clinical findings for VGCC antibody disease vary depending on antibody titer ${ }^{[96]}$. A recent case series review by Zalewski et al. ${ }^{[95]}$ divided patients into groups on the basis of antibody titer and determined which clinical findings were most common in each group. High antibody levels (> $0.99 \mathrm{nmol} / \mathrm{L})$ were associated with encephalopathy, LES, cerebellar ataxia, and peripheral neuropathy. Moderate antibody values were associated with peripheral neuropathy, non-neurologic disorders, cognitive disorders, autonomic neuropathy/dysautonomia, radiculopathy, neuromuscular junction disorder, myopathy, and seizures ${ }^{[95]}$. Lower antibody values were associated with peripheral neuropathy, non-neurologic disorders, cognitive disorders, autonomic neuropathy/dysautonomia, anterior horn cell disorder, seizures, parkinsonism, CNS demyelinating disease, and cerebellar ataxia ${ }^{[95]}$.

VGCC antibodies can be detected in patient serum ${ }^{[95,97,98]}$. Elevated protein has been found in $81 \%$ of CSF samples ${ }^{[95]}$. Leukocytosis is also common, and patients with leukocytosis are more likely to respond to immunotherapy ${ }^{[95]}$. EEG and MRI data for this patient population is sparse. In a report by Finkel et al. ${ }^{[97]}$ concerning a 14-year-old boy who presented with memory dysfunction, mood change, and transient fever, overnight vEEG demonstrated "marked left hemisphere dysfunction, a lack of a posterior dominant rhythm on the left and epileptogenicity with temporal and occipital maximum". EEG also showed several "20- to 30-second-long, subtle/stuttering electrographic seizures emanating from the left hemisphere" ${ }^{\text {,[97] }}$. MRI showed involvement of the hippocampus and temporal lobes ${ }^{[97]}$.

Anti-epileptic drugs such as fos-phenytoin and topiramate may be necessary for patients who present with seizures ${ }^{[97]}$. Immunotherapy is modestly effective in patients with VGCC antibody disease with reports demonstrating use of IV or oral steroids, IVIG, plasma exchange, or other agents such as mycophenolate mofetil, azathioprine, methotrexate, and rituximab ${ }^{[95]}$, where $86 \%$ of patients demonstrate no response or modest response ${ }^{[95]}$.

\section{PARANEOPLASTIC ANTIBODIES}

Paraneoplastic antibodies are involved in an immune process involving both B and $\mathrm{T}$ cells that participate in cytotoxic $\mathrm{T}$ cell-mediated neuronal destruction and neural autoantibody uptake ${ }^{[1]}$. They are described to be linked with neurologic syndromes that arise from underlying cancer ${ }^{[1]}$.

\section{Amphiphysin antibodies}

Amphiphysin is a protein hypothesized to be involved in the process of endocytosis by the recruitment of dynamin, and the subsequent generation of clathrin pits after neurotransmitter exocytosis in mammals ${ }^{[99]}$. It was first discussed in the 1990s, where it was isolated from cDNA expression libraries in chicken and rat models and localized to the presynaptic sites of the brain, adrenals, and anterior and posterior pituitary ${ }^{[99]}$.

There are two major transcription variants of amphiphysin based on alternative splicing. Amphiphysin I is thought to be focused in the nerve terminal, whereas amphiphysin II is concentrated around T-tubules in skeletal muscle and the cytomatrix beneath the plasma membrane of axon initial segments and nodes of Ranvier in the brain ${ }^{[100]}$. 
Antibodies to amphiphysin have been associated with various paraneoplastic disorders and cancers including SPS $^{[101]}$, SCLC $^{[102]}$, and transverse myelitis ${ }^{[102]}$. However, correlation between the presence of antibodies and the prevalence of disease is not clear with Saiz et al. ${ }^{[101]}$ demonstrating the presence of amphiphysin autoantibodies in only $2.9 \%$ of patients with paraneoplastic disease, and $1.4 \%$ of patients with SCLC without paraneoplastic disease ${ }^{[103]}$. Interestingly, it was also found in this study that all patients with amphiphysin antibodies had common reactivity within the $\mathrm{C}$ terminus of the protein, which was previously demonstrated by Lichte et al ${ }^{[99]}$ to be generally devoid of basic amino acids in rat and chicken models. This leads to the hypothesis that casein kinase II is a major component of DNA repair in this portion of the amphiphysin genome.

The correlation of amphiphysin antibodies with $\mathrm{AE}$ remains unclear. One retrospective study showed that only 1 out of 61 people (1.64\%) with AE tested positive for the presence of amphiphysin antibodies ${ }^{[8]}$.

\section{ANNA-1 autoantibodies}

Type 1 antineuronal nuclear autoantibody, also known as ANNA-1, is an antibody to a regulatory neuronal RNA-binding protein. There is a well-documented correlation between the presence of these autoantibodies and paraneoplastic syndromes, including SCLC, with one study finding that $88 \%$ of patients with SCLC were seropositive for ANNA- ${ }^{[104]}$. In addition, a wide range of neurologic disabilities have been described in the literature in patients with paraneoplastic encephalomyelitis and anti-Hu antibodies, including sensory neuropathy, cerebellar ataxia, and $\mathrm{LE}^{[105]}$.

There is the possibility of a connection between ANNA-1-associated paraneoplastic disorders and epilepsy with case reports of clinical and EEG findings consistent with epilepsia partialis continua ${ }^{[106]}$. One retrospective study indicates that nearly half of ANNA-1 antibody-positive patients exhibited extratemporal EEG abnormalities, including slowing (43\%) and epileptiform (29\%) discharges, and epilepsia partialis continua $(7 \%)^{[107]}$.

\section{CRMP-5 antibodies}

Collapsin response mediator protein-5 (CRMP-5) is one of five proteins in the CRMP family, which is believed to play a role in neurologic development. Although normally downregulated in adult brains, elevation of CRMP-5 levels in adults has been extensively studied and found to be inherently correlated with the incidence of SCLC, thymomas, chorea, cranial neuropathy, peripheral neuropathy, autonomic neuropathy, cerebellar ataxia, dementia, and neuromuscular junction disorders ${ }^{[108-110]}$. Other less common but nevertheless documented associations of autoantibodies to CRMP-5 are paraneoplastic associated basal ganglionitis and encephalitis ${ }^{[111]}$ and perioptic neuritis ${ }^{[112]}$.

One mutational analysis study showed that C-terminal processing of CRMP-5 activates a nuclear localization signal that allows for nuclear translocation of the protein and thus pathologic predisposition to glioblastoma ${ }^{[113]}$.

The association between CRMP- 5 autoimmunity and AE is not commonly reported. However, two patients with positive titers for anti-CRMP-5 antibodies with documented seizure histories and characteristic EEG findings both achieved seizure improvement or seizure freedom after IV methylprednisolone treatment ${ }^{[1]}$.

\section{GAD65 autoantibodies}

Glutamic acid decarboxylase (GAD65), a synaptic vesicle-associated antigen, is responsible for the enzymatic conversion of glycine to gamma aminobutyric acid (GABA). Elevations in GAD65 autoantibodies are commonly seen in patients with T1D and are associated with other pathologies including SPS ${ }^{[114]}$, cerebellar ataxia, LE, extrapyramidal symptoms ${ }^{[115]}$, paraneoplastic neurologic syndromes ${ }^{[116]}$, and epilepsy $^{[117-119]}$. 
There have been attempts to tease out the subtle differences between GAD65 antibody elevations in patients with T1D and those with elevations due to other neurologic symptoms. One distinct characteristic between the two is that if anti-GAD65 titers are significantly elevated, patients are more likely to present with concomitant neurologic syndromes in addition to $\mathrm{T}_{1} \mathrm{D}^{[120]}$. Another distinction was the disease-specific GAD65 antibody epitope patterns between T1D, epilepsy, and SPS, with the suggestion that the epileptic etiology in patients diagnosed with both T1D and epilepsy may have distinctly different etiologies with regard to their epileptic condition ${ }^{[120]}$.

Neuroimaging in GAD65-associated epileptic conditions have revealed disproportionate parenchymal atrophy for age with associated abnormal cortical/subcortical T2 hyperintensities ${ }^{[121]}$.

Although there are cases of treatment for GAD-associated AE ranging from cyclophosphamide ${ }^{[122]}$ to testosterone replacement therapy ${ }^{[123]}$, overall immunotherapy is poor ${ }^{[124]}$.

\section{Antineuronal antibodies Ma1 and Ma2}

Antineuronal antibodies Ma1 and Ma2 are involved with RNA transcription regulation and are implicated in various pathologies depending on whatever combination of autoantibodies are present. Patients with isolated Ma2 antibodies (also known as Ta) are more likely to be young males that present with either isolated/ combined/limbic/diencephalic encephalitis or brainstem involvement. The primary cancer in this group is testicular germ cell tumors and these patients have more favorable clinical outcomes, although the majority will deteriorate ${ }^{[125,126]}$. Patients with Ma1 activity are more likely to have complications, including cervical ${ }^{[127]}$, breast $^{[128]}$, lung and bladder cancers ${ }^{[129]}$. The clinical outcomes and prognosis for this group are worse with poor response to immunotherapy.

\section{CONCLUSION}

While the most extensively studied antibodies include NMDAR, VGKC complex with LGI1 and CASPR2 specificities, $G_{A B A_{B}} R$ and $G_{A B A} R$, the antibodies most closely associated with $A E$ are those related to the VGKC complex, namely GAD65 and NMDAR antigens ${ }^{[1]}$. Less frequently identified are $G_{A B A} R, G A B A_{B} R$, glycine receptor, and AMPAR antibodies ${ }^{[1]}$. Even less frequently identified are the paraneoplastic antibodies discussed in the latter half of this review ${ }^{[1]}$. According to the literature, it is likely the case that antibodies associated with $\mathrm{AE}$ are undiagnosed due to the current lack of universally available testing ${ }^{[1]}$. Combined with the limited data of patient populations that are available, there is much work to be done to elucidate the immunological basis of epilepsy.

An important takeaway of this review is that clinicians should be cognizant of the strong association between epilepsy and autoimmune disorders. Unfortunately, symptoms are often dismissed or misdiagnosed, and this can greatly delay early initiation of immunosuppressive treatments in patients who may have otherwise achieved either seizure freedom or a substantial reduction in seizure frequency. An accurate clinical approach that selects at-risk patients on the basis of clinical features, neural autoantibodies, and their response to immunotherapy is recommended to prevent protracted clinical courses.

As the association between the type of antibody detected and its clinical presentation evolves over time, the recognition of $\mathrm{AE}$ will increase. This recognition of immune-mediated epileptogenesis allows for targeted research of the immunological basis of seizure generation. A better understanding of its pathology will lead to refined treatment strategies engineered to address the underlying causes of seizure generation and better outcomes for affected patient populations.

As a concluding note, studies that investigate the effect of lesion location on biomarker levels are lacking, and recent evidence has found that lifestyle factors, such as smoking, fasting, and diet, as well as sample 
processing have caused variability in biomarker analysis ${ }^{[4]}$. In particular, much scrutiny has been placed on sample processing as analysis from plasma and serum are not always correlated ${ }^{[4]}$. While good progress has been made on identifying specific epileptiform events and their associated biomarkers, the literature to date has been criticized due to the lack of replicability in epilepsy biomarker studies, clinical population heterogeneity, and the relatively low power in analysis within the past several years. As such, it is important to emphasize that the use of biomarkers should be used as an adjunct screening tool rather than a diagnosis. Their sensitivity and accuracy in predicting autoimmune origins are not absolute, and care should be taken when evaluating each patient's individual history and symptoms. That said, biomarker studies specifically related to $\mathrm{AE}$ are still in their infancy and would benefit from statistically sufficient clinical studies and standardized approaches to better extract useful data.

\section{DECLARATIONS}

\section{Authors' contributions}

Made substantial contributions to the acquisition and interpretation of intellectual content: Kirmani BF, Au K, Mir S, Hogan M, Kim D, Sharma P

\section{Availability of data and materials}

Not applicable.

\section{Financial support and sponsorship}

None.

\section{Conflicts of interest}

All authors declared that there are no conflicts of interest.

\section{Ethical approval and consent to participate}

Not applicable.

\section{Consent for publication}

Not applicable.

\section{Copyright}

(c) The Author(s) 2021.

\section{REFERENCES}

1. Quek AM, Britton JW, McKeon A, So E, Lennon VA, et al. Autoimmune epilepsy: clinical characteristics and response to immunotherapy. Arch Neurol 2012;69:582-93.

2. Quek AML, O’Toole O. Autoimmune epilepsy: the evolving science of neural autoimmunity and its impact on epilepsy management. Semin Neurol 2018;38:290-302.

3. Graus F, Titulaer MJ, Balu R, Benseler S, Bien CG, et al. A clinical approach to diagnosis of autoimmune encephalitis. Lancet Neurol 2016;15:391-404.

4. Pitkänen A, Ekolle Ndode-Ekane X, Lapinlampi N, Puhakka N. Epilepsy biomarkers - Toward etiology and pathology specificity. Neurobiol Dis 123:42-58.

5. Bermeo-Ovalle A. Scratching the surface in autoimmune epilepsy: it is the time to dig deeper, but how? Epilepsy Curr 2017;17:225-6.

6. Dubey D, Alqallaf A, Hays R, Freeman M, Chen K, et al. Neurological autoantibody prevalence in epilepsy of unknown etiology. JAMA Neurol 2017;74:397-402.

7. Ong MS, Kohane IS, Cai T, Gorman MP, Mandl KD. Population-level evidence for an autoimmune etiology of epilepsy. JAMA Neurol 2014;71:569-74.

8. Lv RJ, Ren HT, Guan HZ, Cui T, Shao XQ. Seizure semiology: an important clinical clue to the diagnosis of autoimmune epilepsy. Ann Clin Transl Neurol 2018;5:208-15.

9. Greco A, Rizzo MI, Virgilio AD, Conte M, Gallo A, et al. Autoimmune epilepsy. Autoimmun Rev 2016;15:221-5.

10. Higdon LM. Autoimmune epilepsy: more than just a paraneoplastic syndrome. 2018. Available from: https://www.semanticscholar.org/ 
paper/Autoimmune-Epilepsy-\%3A-More-Than-Just-A-Syndrome-Higdon/be670cccf8fdfe6e619a5e87464001dd131358b1 [Last accessed on 7 Jul 2020]

11. Lai M, Hughes EG, Peng X, Zhou L, Gleichman AJ, et al. AMPA receptor antibodies in limbic encephalitis alter synaptic receptor location. Ann Neurol 2009;65:424-34.

12. Höftberger R, van Sonderen A, Leypoldt F, Houghton D, Geschwind M, et al. Encephalitis and AMPA receptor antibodies: novel findings in a case series of 22 patients. Neurology 2015;84:2403-12.

13. Peng X, Hughes EG, Moscato EH, Parsons TD, Dalmau J, et al. Cellular plasticity induced by anti- $\alpha$-amino-3-hydroxy-5-methyl-4isoxazolepropionic acid (AMPA) receptor encephalitis antibodies. Ann Neurol 2015;77:381-98.

14. Gleichman AJ, Panzer JA, Baumann BH, Dalmau J, Lynch DR. Antigenic and mechanistic characterization of anti-AMPA receptor encephalitis. Ann Clin Transl Neurol 2014;1:180-9.

15. Joubert B, Kerschen P, Zekeridou A, Desestret V, Rogemond V, et al. Clinical spectrum of encephalitis associated with antibodies against the $\alpha$-Amino-3-Hydroxy-5-Methyl-4-isoxazolepropionic acid receptor: case series and review of the literature. JAMA Neurol 2015;72:1163-9.

16. Saiz A, Blanco Y, Sabater L, González F, Bataller L, et al. Spectrum of neurological syndromes associated with glutamic acid decarboxylase antibodies: diagnostic clues for this association. Brain 2008;131:2553-63.

17. Malter MP, Frisch C, Schoene-Bake JC, Helmstaedter C, Wandinger KP, et al. Outcome of limbic encephalitis with VGKC-complex antibodies: relation to antigenic specificity. J Neurol 2014;261:1695-705.

18. Barajas RF, Collins DE, Cha S, Geschwind MD. Adult-onset drug-refractory seizure disorder associated with anti-voltage-gated potassium-channel antibody. Epilepsia 2010;51:473-7.

19. McKnight K, Jiang Y, Hart Y, Cavey A, Wroe S, et al. Serum antibodies in epilepsy and seizure-associated disorders. Neurology 2005;65:1730-6.

20. Hart IK, Waters C, Vincent A, Newland C, Beeson D, et al. Autoantibodies detected to expressed K+ channels are implicated in neuromyotonia. Ann Neurol 1997;41:238-46.

21. Barber PA, Anderson NE, Vincent A. Morvan's syndrome associated with voltage-gated K+ channel antibodies. Neurology 2000;54:771-2.

22. Josephs KA, Silber MH, Fealey RD, Nippoldt TB, Auger RG, et al. Neurophysiologic studies in Morvan syndrome. J Clin Neurophysiol 2004;21:440-5.

23. Irani SR, Alexander S, Waters P, Kleopa KA, Pettingill P, et al. Antibodies to Kv1 potassium channel-complex proteins leucine-rich, glioma inactivated 1 protein and contactin-associated protein-2 in limbic encephalitis, Morvan's syndrome and acquired neuromyotonia. Brain 2010;133:2734-48.

24. Buckley C, Oger J, Clover L, Tüzün E, Carpenter K, et al. Potassium channel antibodies in two patients with reversible limbic encephalitis. Ann Neurol 2001;50:73-8.

25. Graus F, Saiz A, Lai M, Bruna J, López F, et al. Neuronal surface antigen antibodies in limbic encephalitis: clinical-immunologic associations. Neurology 2008;71:930-6.

26. Kotsenas AL, Watson RE, Pittock SJ, Britton JW, Hoye SL, et al. MRI findings in autoimmune voltage-gated potassium channel complex encephalitis with seizures: one potential etiology for mesial temporal sclerosis. AJNR Am J Neuroradiol 2014;35:84-9.

27. Urbach H, Soeder BM, Jeub M, Klockgether T, Meyer B, et al. Serial MRI of limbic encephalitis. Neuroradiology 2006;48:380-6.

28. Lai M, Huijbers MG, Lancaster E, Graus F, Bataller L, et al. Investigation of LGI1 as the antigen in limbic encephalitis previously attributed to potassium channels: a case series. Lancet Neurol 2010;9:776-85.

29. Fukata Y, Lovero KL, Iwanaga T, Watanabe A, Yokoi N, et al. Disruption of LGI1-linked synaptic complex causes abnormal synaptic transmission and epilepsy. Proc Natl Acad Sci U S A 2010;107:3799-804.

30. Chernova OB, Somerville RP, Cowell JK. A novel gene, LGI1, from 10q24 is rearranged and downregulated in malignant brain tumors. Oncogene 1998;17:2873-81.

31. Kunapuli P, Chitta KS, Cowell JK. Suppression of the cell proliferation and invasion phenotypes in glioma cells by the LGI1 gene. Oncogene 2003;22:3985-91.

32. Kunapuli P, Kasyapa CS, Hawthorn L, Cowell JK. LGI1, a putative tumor metastasis suppressor gene, controls in vitro invasiveness and expression of matrix metalloproteinases in glioma cells through the ERK1/2 pathway. J Biol Chem 2004;279:23151-7.

33. Gu W, Brodtkorb E, Steinlein OK. LGI1 is mutated in familial temporal lobe epilepsy characterized by aphasic seizures. Ann Neurol 2002;52:364-7.

34. Kalachikov S, Evgrafov O, Ross B, Winawer M, Barker-Cummings C, et al. Mutations in LGI1 cause autosomal-dominant partial epilepsy with auditory features. Nat Genet 2002;30:335-41.

35. Morante-Redolat JM, Gorostidi-Pagola A, Piquer-Sirerol S, Sáenz A, Poza JJ, et al. Mutations in the LGI1/Epitempin gene on 10q24 cause autosomal dominant lateral temporal epilepsy. Hum Mol Genet 2002;11:1119-28.

36. Poza JJ, Saenz A, Martinez-Gil A, Cheron N, Cobo AM, et al. Autosomal dominant lateral temporal epilepsy: clinical and genetic study of a large basque pedigree linked to chromosome 10q. Ann Neurol 1999;45:182-8.

37. Scheel H, Tomiuk S, Hofmann K. A common protein interaction domain links two recently identified epilepsy genes. Hum Mol Genet 2002;11:1757-62.

38. Buchanan SG, Gay NJ. Structural and functional diversity in the leucine-rich repeat family of proteins. Prog Biophys Mol Biol 1996;65:144.

39. van Sonderen A, Thijs RD, Coenders EC, Jiskoot LC, Sanchez E, et al. Anti-LGI1 encephalitis: clinical syndrome and long-term follow- 
up. Neurology 2016;87:1449-56.

40. Irani SR, Michell AW, Lang B, Pettingill P, Waters P, et al. Faciobrachial dystonic seizures precede Lgil antibody limbic encephalitis. Ann Neurol 2011;69:892-900.

41. Irani SR, Stagg CJ, Schott JM, Rosenthal CR, Schneider SA, et al. Faciobrachial dystonic seizures: the influence of immunotherapy on seizure control and prevention of cognitive impairment in a broadening phenotype. Brain 2013;136:3151-62.

42. Aurangzeb S, Symmonds M, Knight RK, Kennett R, Wehner T, et al. LGI1-antibody encephalitis is characterised by frequent, multifocal clinical and subclinical seizures. Seizure 2017;50:14-7.

43. Navarro V, Kas A, Apartis E, Chami L, Rogemond V, et al; collaborators. Motor cortex and hippocampus are the two main cortical targets in LGI1-antibody encephalitis. Brain 2016;139:1079-93.

44. Poliak S, Gollan L, Martinez R, Custer A, Einheber S, et al. Caspr2, a new member of the neurexin superfamily, is localized at the juxtaparanodes of myelinated axons and associates with K+ channels. Neuron 1999;24:1037-47.

45. Lancaster E, Huijbers MG, Bar V, Boronat A, Wong A, et al. Investigations of caspr2, an autoantigen of encephalitis and neuromyotonia. Ann Neurol 2011;69:303-11.

46. Strauss KA, Puffenberger EG, Huentelman MJ, Gottlieb S, Dobrin SE, et al. Recessive symptomatic focal epilepsy and mutant contactinassociated protein-like 2. N Engl J Med 2006;354:1370-7.

47. Alarcón M, Abrahams BS, Stone JL, Duvall JA, Perederiy JV, et al. Linkage, association, and gene-expression analyses identify CNTNAP2 as an autism-susceptibility gene. Am J Hum Genet 2008;82:150-9.

48. Friedman JI, Vrijenhoek T, Markx S, Janssen IM, van der Vliet WA, et al. CNTNAP2 gene dosage variation is associated with schizophrenia and epilepsy. Mol Psychiatry 2008;13:261-6.

49. Zweier C, de Jong EK, Zweier M, Orrico A, Ousager LB, et al. CNTNAP2 and NRXN1 are mutated in autosomal-recessive Pitt-Hopkinslike mental retardation and determine the level of a common synaptic protein in Drosophila. Am J Hum Genet 2009;85:655-66.

50. Pinatel D, Hivert B, Boucraut J, Saint-Martin M, Rogemond V, et al. Inhibitory axons are targeted in hippocampal cell culture by antiCaspr2 autoantibodies associated with limbic encephalitis. Front Cell Neurosci 2015;9:265.

51. van Sonderen A, Ariño H, Petit-Pedrol M, Leypoldt F, Körtvélyessy P, et al. The clinical spectrum of Caspr2 antibody-associated disease. Neurology 2016;87:521-8,

52. Joubert B, Saint-Martin M, Noraz N, Picard G, Rogemond V, et al. Characterization of a subtype of autoimmune encephalitis with anti-contactin-associated protein-like 2 antibodies in the cerebrospinal fluid, prominent limbic symptoms, and seizures. JAMA Neurol 2016;73:1115-24.

53. Sunwoo JS, Lee ST, Byun JI, Moon J, Shin JW, et al. Clinical manifestations of patients with CASPR2 antibodies. J Neuroimmunol $2015 ; 281: 17-22$.

54. Ekizoglu E, Tuzun E, Woodhall M, Lang B, Jacobson L, et al. Investigation of neuronal autoantibodies in two different focal epilepsy syndromes. Epilepsia 2014;55:414-22.

55. Baysal-Kirac L, Tuzun E, Erdag E, Ulusoy C, Vanli-Yavuz EN, et al. Neuronal autoantibodies in epilepsy patients with peri-ictal autonomic findings. J Neurol 2016;263:455-66.

56. Shin YW, Lee ST, Shin JW, Moon J, Lim JA, et al. VGKC-complex/LGI1-antibody encephalitis: clinical manifestations and response to immunotherapy. J Neuroimmunol 2013;265:75-81.

57. Boronat A, Gelfand JM, Gresa-Arribas N, Jeong HY, Walsh M, et al. Encephalitis and antibodies to dipeptidyl-peptidase-like protein-6, a subunit of Kv4.2 potassium channels. Ann Neurol 2013;73:120-8.

58. Clark BD, Kwon E, Maffie J, Jeong HY, Nadal M, et al. DPP6 localization in brain supports function as a Kv4 channel associated protein. Front Mol Neurosci 2008;1:8.

59. Piepgras J, Höltje M, Michel K, Li Q, Otto C, et al. Anti-DPPX encephalitis: pathogenic effects of antibodies on gut and brain neurons. Neurology 2015;85:890-7.

60. Tobin WO, Lennon VA, Komorowski L, Probst C, Clardy SL, et al. DPPX potassium channel antibody: frequency, clinical accompaniments, and outcomes in 20 patients. Neurology 2014;83:1797-803.

61. Stokin GB, Popović M, Gelpi E, Kogoj A, Dalmau J, et al. Neuropathologic features of anti-dipeptidyl-peptidase-like protein-6 antibody encephalitis. Neurology 2015;84:430-2.

62. Balint B, Jarius S, Nagel S, Haberkorn U, Probst C, et al. Progressive encephalomyelitis with rigidity and myoclonus: a new variant with DPPX antibodies. Neurology 2014;82:1521-8.

63. Hara M, Ariño H, Petit-Pedrol M, Sabater L, Titulaer MJ, et al. DPPX antibody-associated encephalitis: main syndrome and antibody effects. Neurology 2017;88:1340-8.

64. Stoeck K, Carstens PO, Jarius S, Raddatz D, Stöcker W, et al. Prednisolone and azathioprine are effective in DPPX antibody-positive autoimmune encephalitis. Neurol Neuroimmunol Neuroinflamm 2015;2:e86.

65. Petit-Pedrol M, Armangue T, Peng X, Bataller L, Cellucci T, et al. Encephalitis with refractory seizures, status epilepticus, and antibodies to the GABAA receptor: a case series, characterization of the antigen, and analysis of the effects of antibodies. Lancet Neurol 2014;13:276-86.

66. Ohkawa T, Satake S, Yokoi N, Miyazaki Y, Ohshita T, et al. Identification and characterization of GABA(A) receptor autoantibodies in autoimmune encephalitis. J Neurosci 2014;34:8151-63.

67. Spatola M, Petit-Pedrol M, Simabukuro MM, Armangue T, Castro FJ, et al. Investigations in $\mathrm{GABA}_{\mathrm{A}}$ receptor antibody-associated encephalitis. Neurology 2017;88:1012-20.

68. Benarroch EE. GABAA receptor heterogeneity, function, and implications for epilepsy. Neurology 2007;68:612-4. 
69. Zhou C, Huang Z, Ding L, Deel ME, Arain FM, et al. Altered cortical GABAA receptor composition, physiology, and endocytosis in a mouse model of a human genetic absence epilepsy syndrome. J Biol Chem 2013;288:21458-72.

70. Tanaka M, Olsen RW, Medina MT, Schwartz E, Alonso ME, et al. Hyperglycosylation and reduced GABA currents of mutated GABRB3 polypeptide in remitting childhood absence epilepsy. Am J Hum Genet 2008;82:1249-61.

71. Lancaster E, Lai M, Peng X, Hughes E, Constantinescu R, et al. Antibodies to the GABAB receptor in limbic encephalitis with seizures: case series and characterisation of the antigen. Lancet Neurol 2010;9:67-76.

72. Höftberger R, Titulaer MJ, Sabater L, Dome B, Rózsás A, et al. Encephalitis and GABAB receptor antibodies: novel findings in a new case series of 20 patients. Neurology 2013;81:1500-6.

73. Boronat A, Sabater L, Saiz A, Dalmau J, Graus F. GABA(B) receptor antibodies in limbic encephalitis and anti-GAD-associated neurologic disorders. Neurology 2011;76:795-800.

74. Jeffery OJ, Lennon VA, Pittock SJ, Gregory JK, Britton JW, et al. GABAB receptor autoantibody frequency in service serologic evaluation. Neurology 2013;81:882-7.

75. Bettler B, Kaupmann K, Mosbacher J, Gassmann M. Molecular structure and physiological functions of GABA(B) receptors. Physiol Rev 2004;84:835-67.

76. Luján R, Shigemoto R. Localization of metabotropic GABA receptor subunits GABAB1 and GABAB2 relative to synaptic sites in the rat developing cerebellum. Eur J Neurosci 2006;23:1479-90.

77. Fang B, McKeon A, Hinson SR, Kryzer TJ, Pittock SJ, et al. Autoimmune glial fibrillary acidic protein astrocytopathy: a novel meningoencephalomyelitis. JAMA Neurol 2016;73:1297-307.

78. Iorio R, Damato V, Evoli A, Gessi M, Gaudino S, et al. Clinical and immunological characteristics of the spectrum of GFAP autoimmunity: a case series of 22 patients. J Neurol Neurosurg Psychiatry 2018;89:138-46.

79. Flanagan EP, Hinson SR, Lennon VA, Fang B, Aksamit AJ, et al. Glial fibrillary acidic protein immunoglobulin G as biomarker of autoimmune astrocytopathy: analysis of 102 patients. Ann Neurol 2017;81:298-309.

80. Hutchinson M, Waters P, McHugh J, Gorman G, O’Riordan S, et al. Progressive encephalomyelitis, rigidity, and myoclonus: a novel glycine receptor antibody. Neurology 2008;71:1291-2.

81. Swayne A, Tjoa L, Broadley S, Dionisio S, Gillis D, et al. Antiglycine receptor antibody related disease: a case series and literature review. Eur J Neurol 2018;25:1290-8.

82. Carvajal-González A, Leite MI, Waters P, Woodhall M, Coutinho E, et al. Glycine receptor antibodies in PERM and related syndromes: characteristics, clinical features and outcomes. Brain 2014;137:2178-92.

83. Zuliani L, Ferlazzo E, Andrigo C, Casano A, Cianci V, et al. Glycine receptor antibodies in 2 cases of new, adult-onset epilepsy. Neurol Neuroimmunol Neuroinflamm 2014;1:e16.

84. Lancaster E, Martinez-Hernandez E, Titulaer MJ, Boulos M, Weaver S, et al. Antibodies to metabotropic glutamate receptor 5 in the Ophelia syndrome. Neurology 2011;77:1698-701.

85. Nicoletti F, Bockaert J, Collingridge GL, Conn PJ, Ferraguti F, et al. Metabotropic glutamate receptors: from the workbench to the bedside. Neuropharmacology 2011;60:1017-41.

86. Simonyi A, Schachtman TR, Christoffersen GR. Metabotropic glutamate receptor subtype 5 antagonism in learning and memory. Eur J Pharmacol 2010;639:17-25.

87. Spatola M, Sabater L, Planagumà J, Martínez-Hernandez E, Armangué T, et al. Encephalitis with mGluR5 antibodies: Symptoms and antibody effects. Neurology 2018;90:e1964-72.

88. Li F, Tsien JZ. Memory and the NMDA receptors. N Engl J Med 2009;361:302-3.

89. Vitaliani R, Mason W, Ances B, Zwerdling T, Jiang Z, et al. Paraneoplastic encephalitis, psychiatric symptoms, and hypoventilation in ovarian teratoma. Ann Neurol 2005;58:594-604.

90. Dalmau J, Gleichman AJ, Hughes EG, Rossi JE, Peng X, et al. Anti-NMDA-receptor encephalitis: case series and analysis of the effects of antibodies. Lancet Neurol 2008;7:1091-8.

91. Dalmau J, Lancaster E, Martinez-hernandez E, Rosenfeld MR, Balice-gordon R. Clinical experience and laboratory investigations in patients with anti-NMDAR encephalitis. Lancet Neurol 2011;10:63-74.

92. Titulaer MJ, Mccracken L, Gabilondo I, Armangué T, Glaser C, et al. Treatment and prognostic factors for long-term outcome in patients with anti-NMDA receptor encephalitis: an observational cohort study. Lancet Neurol 2013;12:157-65.

93. Schmitt SE, Pargeon K, Frechette ES, Hirsch LJ, Dalmau J, et al. Extreme delta brush: a unique EEG pattern in adults with anti-NMDA receptor encephalitis. Neurology 2012;79:1094-100.

94. Prüss H, Dalmau J, Harms L, Holtje M, Ahnert-Hilger G, et al. Retrospective analysis of NMDA receptor antibodies in encephalitis of unknown origin. Neurology 2010;75:1735-9.

95. Zalewski NL, Lennon VA, Lachance DH, Klein CJ, Pittock SJ, et al. P/Q- and N-type calcium-channel antibodies: oncological, neurological, and serological accompaniments. Muscle Nerve 2016;54:220-7.

96. Lennon VA, Kryzer TJ, Griesmann GE, O’Suilleabhain PE, Windebank AJ, et al. Calcium-channel antibodies in the lambert-eaton syndrome and other paraneoplastic syndromes. N Engl J Med 1995;332:1467-74.

97. Finkel L, Koh S. N-type calcium channel antibody-mediated autoimmune encephalitis: An unlikely cause of a common presentation. Epilepsy Behav Case Rep 2013;1:92-6.

98. Younes K, Lepow LA, Estrada C, Schulz PE. Auto-antibodies against P/Q- and N-type voltage-dependent calcium channels mimicking frontotemporal dementia. SAGE Open Med Case Rep 2018;6:2050313X17750928.

99. Lichte B, Veh R, Meyer H, Kilimann M. Amphiphysin, a novel protein associated with synaptic vesicles. EMBO J 1992;11:2521-30. 
100. Butler MH, David C, Ochoa GC, Freyberg Z, Daniell L, et al. Amphiphysin II (SH3P9; BIN1), a member of the amphiphysin/Rvs family, is concentrated in the cortical cytomatrix of axon initial segments and nodes of ranvier in brain and around T tubules in skeletal muscle. $\mathrm{J}$ Cell Biol 1997;137:1355-67.

101. Saiz A, Dalmau J, Butler MH, Chen Q, Delattre JY, et al. Anti-neuronal antibodies in paraneoplastic neurological disorders with smallcell lung carcinoma. J Neurol Neurosurg Psychiatry 1999;66:214-7.

102. McKeon A, Pittock SJ, Lennon VA. Stiff-person syndrome with amphiphysin antibodies: distinctive features of a rare disease. Neurology 2009;73:2132; author reply 2133 .

103. Faissner S, Lukas C, Reinacher-Schick A, Tannapfel A, Gold R, et al. Amphiphysin-positive paraneoplastic myelitis and stiff-person syndrome. Neurol Neuroimmunol Neuroinflamm 2016;3:e285.

104. Lucchinetti CF, Kimmel DW, Lennon VA. Paraneoplastic and oncologic profiles of patients seropositive for type 1 antineuronal nuclear autoantibodies. Neurology 1998;50:652-7.

105. Graus F, Keime-Guibert F, Reñe R, Benyahia B, Ribalta T, et al. Anti-Hu-associated paraneoplastic encephalomyelitis: analysis of 200 patients. Brain 2001;124:1138-48.

106. Shavit YB, Graus F, Probst A, Rene R, Steck AJ. Epilepsia partialis continua: a new manifestation of anti-Hu-associated paraneoplastic encephalomyelitis. Ann Neurol 1999;45:255-8.

107. Rudzinski LA, Pittock SJ, McKeon A, Lennon VA, Britton JW. Extratemporal EEG and MRI findings in ANNA-1 (anti-Hu) encephalitis. Epilepsy Res 2011;95:255-62.

108. Yu Z, Kryzer TJ, Griesmann GE, Kim K, Benarroch EE, et al. CRMP-5 neuronal autoantibody: marker of lung cancer and thymomarelated autoimmunity. Ann Neurol 2001;49:146-54.

109. Aydin D, Somnier F, Lassen LH. Paraneoplastic choreoathetosis in a patient with small cell lung carcinoma and anti-CRMP5/CV2: a case report. Case Rep Neurol 2016;8:16-9.

110. Vernino S, Tuite P, Adler CH, Meschia JF, Boeve BF, et al. Paraneoplastic chorea associated with CRMP-5 neuronal antibody and lung carcinoma. Ann Neurol 2002;51:625-30.

111. Maramattom BV. Paraneoplastic CRMP-5 basal ganglionitis and limbic encephalitis in an elderly Indian lady. Neurol India 2013;61:534-5.

112. Igarashi N, Sawamura H, Kaburaki T, Aihara M. Anti-collapsing response-mediating protein-5 antibody-positive paraneoplastic perioptic neuritis without typical neurological symptoms. Neuroophthalmology 2017;41:24-9.

113. Brot S, Malleval C, Benetollo C, Auger C, Meyronet D, et al. Identification of a new CRMP5 isoform present in the nucleus of cancer cells and enhancing their proliferation. Exp Cell Res 2013;319:588-99.

114. Solimena M, Folli F, Aparisi R, Pozza G, De Camilli P. Autoantibodies to GABA-ergic neurons and pancreatic beta cells in stiff-man syndrome. N Engl J Med 1990;322:1555-60.

115. Pittock SJ, Yoshikawa H, Ahlskog JE, Tisch SH, Benarroch EE, et al. Glutamic acid decarboxylase autoimmunity with brainstem, extrapyramidal, and spinal cord dysfunction. Mayo Clin Proc 2006;81:1207-14.

116. Ariño H, Höftberger R, Gresa-Arribas N, Martínez-Hernández E, Armangue T, et al. Paraneoplastic neurological syndromes and glutamic acid decarboxylase antibodies. JAMA Neurol 2015;72:874-81.

117. Errichiello L, Perruolo G, Pascarella A, Formisano P, Minetti C, et al. Autoantibodies to glutamic acid decarboxylase (GAD) in focal and generalized epilepsy: A study on 233 patients. J Neuroimmunol 2009;211:120-3.

118. Falip M, Carreño M, Miró J, Saiz A, Villanueva V, et al. Prevalence and immunological spectrum of temporal lobe epilepsy with glutamic acid decarboxylase antibodies. Eur J Neurol 2012;19:827-33.

119. Brenner T, Sills GJ, Hart Y, Howell S, Waters P, et al. Prevalence of neurologic autoantibodies in cohorts of patients with new and established epilepsy. Epilepsia 2013;54:1028-35.

120. Liimatainen S, Honnorat J, Pittock SJ, McKeon A, Manto M, et al; T1D Exchange Biobank. GAD65 autoantibody characteristics in patients with co-occurring type 1 diabetes and epilepsy may help identify underlying epilepsy etiologies. Orphanet J Rare Dis 2018;13:55.

121. Fredriksen JR, Carr CM, Koeller KK, Verdoorn JT, Gadoth A, et al. MRI findings in glutamic acid decarboxylase associated autoimmune epilepsy. Neuroradiology 2018;60:239-45.

122. Kanter IC, Huttner HB, Staykov D, Biermann T, Struffert T, et al. Cyclophosphamide for anti-GAD antibody-positive refractory status epilepticus. Epilepsia 2008;49:914-20.

123. Heiry M, Afra P, Matsuo F, Greenlee JE, Clardy SL. Improvement of GAD65-associated autoimmune epilepsy with testosterone replacement therapy. Neurol Neuroimmunol Neuroinflamm 2015;2:e142.

124. Malter MP, Frisch C, Zeitler H, Surges R, Urbach H, et al. Treatment of immune-mediated temporal lobe epilepsy with GAD antibodies. Seizure 2015;30:57-63.

125. Dalmau J, Graus F, Villarejo A, Posner JB, Blumenthal D, et al. Clinical analysis of anti-Ma2-associated encephalitis. Brain 2004;127:1831-44.

126. Hoffmann LA, Jarius S, Pellkofer HL, Schueller M, Krumbholz M, et al. Anti-Ma and anti-Ta associated paraneoplastic neurological syndromes: 22 newly diagnosed patients and review of previous cases. J Neurol Neurosurg Psychiatry 2008;79:767-73.

127. Ney DE, Messersmith W, Behbakht K. Anti-ma2 paraneoplastic encephalitis in association with recurrent cervical cancer. J Clin Neurol 2014;10:262-6.

128. Sahashi K, Sakai K, Mano K, Hirose G. Anti-Ma2 antibody related paraneoplastic limbic/brain stem encephalitis associated with breast cancer expressing Ma1, Ma2, and Ma3 mRNAs. J Neurol Neurosurg Psychiatry 2003;74:1332-5.

129. Ortega Suero G, Sola-valls N, Escudero D, Saiz A, Graus F. Anti-Ma and anti-Ma2-associated paraneoplastic neurological syndromes. Neurología (English Edition) 2018;33:18-27. 